\title{
O CONSUMO TRANSMÍDIA DA FRANQUIA WORLD OF WARCRAFT: PERCEPÇÕES DE CONSUMIDORES BRASILEIROS
}

\author{
RAFAEL JOSE BONA \\ UNIVERSIDADE REGIONAL DE BLUMENAU \\ BLUMENAU, SANTA CATARINA, BRASIL \\ BONA.PROFESSOR@GMAIL.COM \\ ÉDERSON LUÍS DA SILVEIRA \\ UNIVERSIDADE FEDERAL DE SANTA CATARINA \\ FLORIANÓPOLIS, SANTA CATARINA, BRASIL \\ EDILITERATUS@GMAIL.COM \\ DIOGO DE AZEREDO LEÃO COUTINHO \\ UNIVERSIDADE REGIONAL DE BLUMENAU \\ BLUMENAU, SANTA CATARINA, BRASIL \\ DIOGO-COUTINHO@HOTMAIL.COM
}




\section{O CONSUMO TRANSMÍDIA DA FRANQUIA WORLD OF WARCRAFT: PERCEPÇÕES DE CONSUMIDORES BRASILEIROS}

Resumo: $O$ objetivo deste artigo é analisar os fatores motivacionais que levam os jogadores do game World of Warcraft a consumir suas narrativas em diversas mídias. A pesquisa se classifica como exploratória e descritiva por meio de um questionário subdividido em quatro blocos com perguntas abertas e fechadas, aplicado a jogadores de um grupo dedicado ao jogo, em uma rede social digital. Conclui-se que um dos principais fatores que motivam o consumo do jogo é sua narrativa e a imersão que proporciona aos jogadores.

Palavras-chave: consumo; narrativa transmídia; World of Warcraft.

\section{EL CONSUMO TRANSMEDIA DE LA FRANQUICIA WORLD OF WAR-}

\section{CRAFT: PERCEPCIONES DE LOS CONSUMIDORES BRASILEÑOS}

Resumen: El objetivo de este artículo es analizar los factores motivacionales que llevan a los jugadores del juego World of Warcraft a consumir sus narrativas en diversos medios. La investigación se clasifica como exploratoria y descriptiva a través de un cuestionario subdividido en cuatro bloques con preguntas abiertas y cerradas, aplicado a jugadores de un grupo dedicado al juego, en una red social digital. Se concluye que uno de los principales factores que motivan el consumo del juego es su narrativa y la inmersión que proporciona a los jugadores.

Palabras Clave: consumo; narrativa transmedia; World of Warcraft.

\section{THE TRANSMEDIA CONSUMPTION OF THE WORLD OF WARCRAFT FRANCHISE: PERCEPTIONS OF BRAZILIAN CONSUMERS}

Abstract: The purpose of this paper is to analyze the motivational factors that lead the players in the game World of Warcraft to consume their narratives in various media. The research is classified as exploratory and descriptive type through a questionnaire in four blocks with open and closed questions, applied to players from a group dedicated to the game, in a social network. It is concluded that one of the main factors that motivate the game consumption is your narrative and immersion that provides players. Keywords: consumption; transmedia storytelling; World of Warcraft.

\section{INTRODUÇÃO}

O mercado brasileiro de games ocupa a $13^{\circ}$ posição no ranking global e está situado em primeiro lugar na América Latina (NEWZOO, 2016). Em contrapartida à economia nacional o mercado brasileiro de games teve um cres- 
cimento de 1,5 bilhões de dólares no ano de 2016 contando com mais de 61,2 milhões de jogadores (consoles, computador e mobile) que consomem algum tipo de jogo eletrônico. Para entreter o público e evitar que seus jogos sejam maçantes, muitas produtoras optam por dividir o conteúdo de suas narrativas em diversas mídias, transformando-os em uma narrativa transmídia, fazendo com que os fãs procurem saber mais sobre o game, aprimorando as suas experiências e, tendo assim, uma relação mais heterogênea com a história por meio da apresentação de narrativas em mídias diversas.

A transmedia storytelling ou narrativa transmídia, representa um processo no qual um conjunto de elementos de uma ficção estão dispersos sistematicamente em múltiplas plataformas com o propósito de criar uma experiência unificada e coordenada de entretenimento. Envolve, assim, a criação de universos ficcionais compartilhados pelos diferentes meios, cabendo o desenvolvimento de programas narrativos próprios, mas de modo articulado e complementar com os demais (JENKINS, 2009).

Nesse contexto, a narrativa transmídia no meio publicitário tem sido de grande relevância para o consumo midiático de conteúdo em diversas plataformas. Tal cenário facilitou possíveis desdobramentos do universo ficcional com um potencial para se manifestar em múltiplos meios, expandindo assim o enredo original em distintos momentos da linha temporal. Com isso é possível o enfoque em novos aspectos ou pontos de vista, o que viabiliza melhor exploração de personagens secundários e/ou complexificar a atuação dos protagonistas a partir de situações e ambientes próprios que cada plataforma apresenta.

Covaleski (2015) apresenta o consumo como um fenômeno da cultura contemporânea. Conforme Rocha (2006, p. 12) "o significado que o consumo adquire na sociedade passa pelos significados a ele atribuídos pela publicidade". Desse modo, a construção e (re) produção de significados e os direcionamentos publicitários estão articulados às próprias formas de manifestação cultural hodiernas.

Em sua visão, Scolari (2013, p. 278) diz que "as narrativas transmídia obrigam produtores e roteiristas a pensar em outros termos. Já não se trata de criar um personagem para um determinado meio (livro, cinema, história em quadrinhos ou televisão), senão de desenhar mundos-marca”. Ou seja, o personagem não ficará somente em um determinado meio, ele irá transitar em diversas histórias. A multiplicidade de ambientes e contextos revela uma heterogeneidade constitutiva das narrativas transmídia, visto que tal 
característica se torna sua condição de possibilidade de existência e de proliferação por meio do consumo.

Outrossim, cabe destacar que um conteúdo de mídia passa para diversos meios a fim de evitar a saturação do consumidor. Desse modo, tal conteúdo repercute e reverbera o outro, colabora para manter o interesse, o envolvimento e a intervenção criativa do consumidor de mídias no universo no qual ambos se inserem. Nesse aspecto, torna-se importante compreender os fatores e estímulos que levam ao consumo por meio da transmídia.

Um estudo realizado por Fechine e Bronsztein (2016), criado a partir de uma agenda de investigação de consumo transmídia de conteúdos televisivos, revelou que uma predisposição dos que assistem televisão diariamente ao uso das mídias sociais, indicando assim uma pertinência e potencial elaboração de estratégias transmídia. Os autores utilizaram a televisão como lugar privilegiado de observação ao entender que a produção de conteúdos audiovisuais não está desarticulada de conglomerados cada vez mais abrangentes e interconectados de comunicação.

Segundo pesquisa realizada por Justi e Mill (2017), acerca da intersecção entre mídia on e off-line, notou-se que a possibilidade de espalhar discursos por diferentes plataformas também impacta as estratégias de comunicação persuasiva de estímulo ao consumo, na medida em que oferece novos níveis de revelação e de experiências ao público.

Em um estudo específico sobre a construção de mundos articulados entre as abordagens dos projetistas e dos usuários, Oliveira e Massarolo (2011) identificam que no âmbito da construção de um mundo de histórias, o projeto deve ser articulado não somente com o processo de interpretação dos universos narrativos por parte do público, mas, também, com as formas como o público constrói o mundo de acordo com seus próprios enquadramentos.

O objeto deste estudo é a franquia World of Warcraft, desenvolvido pela Blizzard Entertainment, e que nasceu do universo de Warcraft, originando uma das franquias mais bem conceituadas na história dos jogos. Contando com mais de cem milhões de jogadores distribuídos em 224 países e territórios (dados de 2014, informações da produtora) o game conta com diversas histórias, tramas e enredos que envolvem tanto personagens principais e secundários. A narrativa do game está dividida em vários livros, histórias em quadrinhos, animes sendo o filme a adaptação mais recente.

O objetivo geral deste artigo, portanto, é o de analisar os fatores moti- 
vacionais que levam os jogadores brasileiros do game World of Warcraft a consumir suas narrativas em diversas mídias. Os objetivos específicos são: identificar os principais motivos pelos quais ocorre o consumo do game; analisar o nível de envolvimento dos livros por parte dos jogadores; analisar o nível de envolvimento do filme por parte dos jogadores e, por fim, investigar a influência da narrativa no consumo do jogo.

\section{O UNIVERSO DE WORLD OF WARCRAFT}

World of Warcraft, popularmente conhecido como WoW, é um Massively Multiplayer Online Role Playing Game (MMORPG), disponível para as plataformas Windows e Mac, foi lançado pela Blizzard Entertainment em 2004. Rapidamente quebrou todos os recordes anteriores de venda e se tornou um sucesso na América do Norte, na Austrália e na Nova Zelândia. Posteriormente, foi lançado na Coréia do Sul, na Europa, na China, em Cingapura e, em seguida, em Taiwan e Hong Kong. No ano de 2005, em Macau, em 2006 na Malásia e, em 2007, na Tailândia. No momento atual o jogo está disponível em inglês, francês, alemão, espanhol, russo, português, italiano, chinês, coreano e japonês. WoW é considerado o MMORPGs mais popular do mundo, visto que em 2010 chegou a ter mais de 11 milhões de jogadores ativos e em 2016 contou com 5.5 milhões de jogadores regularmente de acordo com dados da própria produtora.

O mundo de Azeroth serve de palco para toda ação do universo Warcraft, sendo um mundo fantasioso que combina narrativa, realização de tarefas, criação de itens, resolução de problemas, negociação, combates e socialização entre outros jogadores. Trata-se de um planeta fictício criado em 1994 para o jogo Warcraft: Orcs \& Humans e utilizado para todos os demais jogos da franquia. Possui quatro continentes e muitas ilhas, é habitado por raças diversas inclusive alienígenas, subdivididas em duas facções: Horda e Aliança (LOPES; MUSTARO, 2009).

Conforme mencionado, para adentrar no mundo de WoW, o jogador deverá escolher entre duas facções políticas que vivem em constante conflito pelo controle do mundo: Horda e Aliança. Cada facção apresenta suas próprias histórias, seus conflitos internos e externos.

Depois de efetuada a escolha, o jogador passa a escolher as raças pertencentes de cada facção. A Horda é composta pelas seguintes raças: Elfos Sangrentos, Orcs, Taurens, Trolls, Renegados, Goblins e Pandarens Houjin. Já a Aliança, é composta pelas seguintes raças: Draeneis, Humanos, Anões, 
Elfos Noturnos, Gnomos, Worgens e Pandaren Tushui.

Por último, é necessário escolher a classe para se aventurar no mundo de Azeroth. Ao total são dez classes: Guerreiro, Paladino, Caçador, Ladino, Sacerdote, Xamã, Mago, Bruxo, Monge e Druida. E também duas classes heroicas: Cavaleiro da Morte e Caçador de Demônios, sendo necessário já possuir um personagem de determinado nível para habilitar. Existem três funções distintas nas classes de WoW: dano, cura e tanque. Cada classe possui especializações para estas determinadas funções, cada uma com uma jogabilidade e mecânica diferentes. Algumas classes apresentam as três funções, duas funções ou apenas uma. Tem-se, então, variabilidade de escolhas de jogador para jogador nas quais cabe a cada um escolher a qual ele se adapta mais ou qual a necessidade do momento.

Para jogar é necessário comprar o jogo base e a última expansão vigente. Após a compra, é necessário pagar uma taxa mensal que permite continuar jogando após os primeiros 30 dias, tornando-se um jogo pay to play (P2P). Existe ainda a compra de tempo in game, cujo valor cobrado é da própria moeda virtual do jogo, seus valores podem variar conforme economia de cada servidor. Ainda assim, é possível jogá-lo de graça, mesmo que de forma limitada. Nesse âmbito, o personagem escolhido nunca avança além do nível 20, sendo o nível máximo do jogo atualmente o nível 110, além de algumas restrições adicionais.

\section{PROCEDIMENTOS METOdOLÓGICOS}

Com intuito de aprofundar o tema proposto e responder aos objetivos apresentados a metodologia utilizada para realização desta pesquisa é considerada exploratória, pois, segundo Barquette e Chaoubah (2007, p. 24), "considera-se pesquisa exploratória inicial a busca de dados em fontes secundárias, como: literaturas, documentos internos e uma empresa, conversas com especialistas e pesquisas em internet, entre outras fontes".

Para atingir o objetivo proposto foi utilizada a técnica de roteiro de entrevista. Segundo Barquette e Chaoubah (2007, p. 43):

Roteiros são guias usados por pesquisadores para coletar informações. Diferem dos questionários por não serem estruturados em perguntas e respostas. Contém tópicos sobre assuntos relacionados ao objetivo de pesquisa e conferem ao pesquisador liberdade para modificar a ordem ou inserir questões, de acordo com o andamento da entrevista. 
A pesquisa configura-se como não probabilística. Segundo Virgillito (2010, p. 99):

\begin{abstract}
Amostragem não probabilística é aquela em que existe uma probabilidade diferente de zero de uma variável considerada não pertencer à amostra. Em outras palavras, faz-se uma manipulação a priori da população e extraem-se dela somente os elementos com uma ou mais características.
\end{abstract}

Dessa forma foi aplicado um questionário estruturado utilizando a ferramenta Google Forms para executar a pesquisa entre os dias 23 e 30 de abril de 2018 com jogadores de World of Warcraft presentes no grupo World of Warcraft Brasil na rede social Facebook. O Google Forms é uma ferramenta do Google que permite o desenvolvimento de pesquisas para coleta de opiniões, fazer enquetes, tabular dados, entre outros. Foram obtidas 302 respostas.

Esse grupo conta com mais de 48.000 membros e é o oficial da produtora do jogo Blizzard Entertainment, sendo considerada a maior comunidade brasileira de jogadores nas redes sociais. O questionário ficou aberto até atingir um número significativo de respostas, sendo utilizado o cálculo amostral com nível de confiança em 90\%, fazendo-se necessário atingir o número mínimo de 271 respostas. O questionário possuía quatro blocos relacionados a: perfil do jogador, consumo, narrativa e narrativa transmídia. Esse questionário foi estruturado com o objetivo de atingir todos os objetivos propostos. O objetivo geral é analisar os fatores motivacionais que levam os jogadores brasileiros de WoW a consumir suas narrativas em diversas mídias e os específicos, identificar os principais motivos pelos quais ocorre o consumo do game, analisar o nível de envolvimento dos livros por parte dos jogadores, analisar o nível de envolvimento do filme pelos jogadores e verificar se a publicidade influenciou no consumo de mídia e para que se pudesse trabalhar de forma mais adequada e aprofundada acerca de cada temática. A construção do questionário utilizou a modelagem proposta por Pereira e Bona (2018).

Para o primeiro bloco, foram realizadas sete perguntas para analisar o perfil dos entrevistados. Procurou-se saber sobre a idade do entrevistado, qual o gênero, seu estado atual, visto que o grupo contém jogadores de todo o Brasil, estado civil, se possui filhos ou não, quantas pessoas moram junto ao entrevistado e qual a renda familiar mensal. 
No segundo bloco, foram feitas perguntas para analisar o perfil de consumo de mídia do entrevistado. O bloco era composto por cinco perguntas, sendo qual a primeira a frequência em que o entrevistado lia livros, independente do gênero. A segunda pergunta era sobre qual ou quais eram seus gêneros preferidos de jogos. A terceira pergunta era qual ou quais são seus gêneros preferidos de livros. A quarta era sobre qual ou quais são seus gêneros preferidos de filmes. A quinta e última pergunta foi sobre qual dispositivo o entrevistado mais utiliza para jogar.

Para o terceiro bloco, foram realizadas cinco perguntas a respeito da narrativa de World of Warcraft. A primeira pergunta teve como objetivo saber de que maneira o entrevistado conheceu World of Warcraft. A segunda pergunta procurou responder como o entrevistado avalia o enredo geral de World of Warcraft. A terceira pergunta foi sobre o que mais que o entrevistado gostou na narrativa de World of Warcraft. Devido à possibilidade de criação de vários personagens de diversas classes, a história muda conforme a classe escolhida, então, para a quarta pergunta, buscou-se saber se o entrevistado joga com diversas classes para saber mais da lore, que se refere à narrativa que não é diretamente contada ao jogador. Para a quinta e última pergunta deste bloco tentou identificar se a narrativa de World of Warcraft incentivou a consumir outras mídias (livros, filme, história em quadrinhos).

Para o quarto e último bloco de entrevista, o tema abordado foi narrativa transmídia, que contém no total catorze perguntas. A primeira pergunta esteve relacionada a facção que o entrevistado joga, considerando-se que é possível criar personagens em ambas as facções a fim de compreender meIhor a história. Por conta de possuir uma ampla narrativa, existem diversas mídias que fragmentam a história de World of Warcraft, por conta disso, a segunda foi um comparativo entre a narrativa dos livros em relação ao jogo e ao filme.

A terceira pergunta estabelece um comparativo entre a narrativa do jogo em relação ao filme e aos livros. A quarta pergunta foi o comparativo entre a narrativa do filme em relação ao jogo e aos livros. Para todas essas perguntas foi utilizada uma escala de 1 (um) para péssimo a 10 (dez) para perfeito. A quinta pergunta foi se o entrevistado leria novamente os livros que apresentam a narrativa de World of Warcraft. A sexta foi a respeito do filme e se novamente o assistiria. A sétima pergunta foi a respeito ao jogo, se o entrevistado jogaria novamente os antigos conteúdos, vulgo antigas expansões, já que muitos preferem apenas chegar ao nível máximo do jogo 
mais rapidamente e não exploram todo conteúdo oferecido. A oitava pergunta foi se o entrevistado reconheceu alguma referência do jogo nos livros e no filme. A nona foi se o entrevistado reconheceu alguma referência dos livros no jogo e no filme. A décima questão foi se o reconheceu alguma referência do filme no jogo e nos livros. O décimo primeiro questionamento foi se era possível compreender o conteúdo do jogo isoladamente. A questão de número doze incidiu sobre se era possível compreender o conteúdo dos livros isoladamente. A décima terceira pergunta foi se era possível compreender o filme isoladamente e a décima quarta e última pergunta buscou saber qual a primeira palavra que vem à mente do entrevistado quando se fala World of Warcraft.

$O$ roteiro da pesquisa, apresentado a seguir, foi aplicado com jogadores do World of Warcraft no grupo do Facebook. As perguntas envolvem o perfil dos jogadores, seu consumo de mídia, narrativa e narrativa transmídia. O questionário foi elaborado a partir do estudo de Bona e Souza (2013).

Quadro 1: Roteiro do Questionário

\author{
BLOCO 1 \\ Qual sua idade? \\ Qual seu gênero? \\ Qual seu estado? \\ Estado civil? \\ Possui filhos? \\ Quantas pessoas moram com você? \\ Qual sua renda familiar mensal?
}

\title{
BLOCO 2
}

Com que frequência você lê livros?

Quais/qual são seus gêneros preferidos de jogos?

Quais/qual são seus gêneros preferido de livros?

Qual/qual são seus gêneros preferido de filmes?

Qual desses dispositivos você mais usa?

\section{$\mathrm{BLOCO}_{3}$}

Como você conheceu World of Warcraft?

Como você avalia o enredo de World of Warcraft?

O que você mais gostou da narrativa de World of Warcraft?

Você joga com diversas classes para saber mais sobre lore?

A narrativa de World of Warcraft incentivou você a consumir outras mídias? (Livro, filmes, HQ's...) 


\section{BLOCO 4}

Em qual facção você joga?

Compare a narrativa dos livros em relação ao jogo e ao filme. (1 para horrível e 10 para perfeito)

Compare a narrativa do jogo em relação ao filme e aos livros. (1 para horrível e 10 para perfeito)

Compare a narrativa do filme em relação ao jogo e aos livros. (1 para horrível e 10 para perfeito)

Você leria novamente os livros?

Você assistiria novamente o filme?

Você jogaria novamente os antigos conteúdos (expansões)?

Você reconhece alguma referência do jogo nos livros e no filme?

Você reconhece alguma referência dos livros no jogo e no filme?

Você reconhece alguma referência do filme no jogo e nos livros?

Você compreende o todo conteúdo do jogo isoladamente?

Você compreende o conteúdo dos livros isoladamente?

Você compreende o conteúdo do filme isoladamente?

Qual a primeira palavra que vem a sua cabeça quando se fala World of Warcraft?

Fonte: dados da pesquisa.

\section{DISCUSSÃO DOS RESULTADOS}

Inicialmente, como o primeiro bloco do questionário tinha como objetivo de descobrir o perfil do jogador, foram feitas perguntas relacionadas à idade, à renda ao gênero e referente ao contexto onde mora. Chegou-se à conclusão de que o perfil do jogador entrevistado de World of Warcraft tem a idade entre 20 e 24 anos, masculino, residente do estado de São Paulo, solteiro, que não possui filhos, mora em duas pessoas e possui uma renda familiar de até três salários mínimos. Como procedimento para determinação dos valores foram escolhidas categorias pré-determinadas que apresentaram maior percentual dentro da amostra.

Para o segundo bloco, cujo objetivo era o de descobrir o nível de consumo do entrevistado, foram feitas perguntas relacionadas à sua frequência de leitura, seus gêneros preferidos de jogos, livros e filmes e qual dispositivo mais usado pelo entrevistado. Na primeira pergunta do bloco, sobre a frequência de leitura de livros, pode-se notar que o "raramente" e o "quase sempre" aparecem entre os mais escolhidos pelos jogadores. 
Figura 1: Frequência de leitura de livros

\section{Com que frequência você lê livros?}

\section{2 responses}

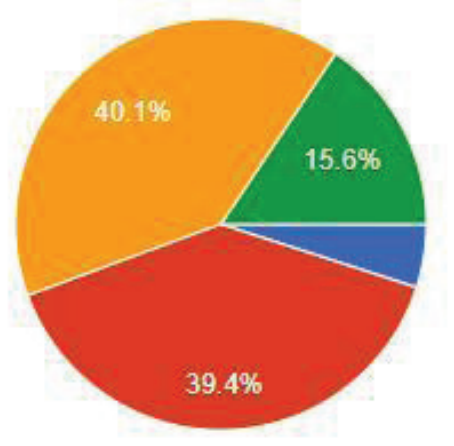

Nunca

Raramente

Quase sempre

Sempre

Fonte: dados da pesquisa.

Em relação aos que optaram pela opção "raramente" pode ser situado que estes procuram pelo menos ler, mas não possuem o hábito da leitura, diferente de quem optou pela opção "sempre". Quanto ao gênero de livros, filmes e jogos preferidos dos entrevistados, pode-se notar uma pré-disposição dos jogadores para filmes que englobam ficção, ação e aventura, pois estes são os mais citados em ambas as perguntas. Para Martins (2009), a narrativa é um ambiente na própria realidade do público; seja ele de ficção, ou de fantasia, quando é criado um lugar fictício para ambientar a narrativa; ou de fantasia, é necessário buscar outros cenários que não os do mundo material. Com isso, World of Warcraft engloba todos os gêneros mais citados, fazendo com que o jogador crie seu próprio mundo fantasioso. Bilgihan et al (2013) discorrem que diversos gêneros de jogos eletrônicos tendem a despertar diferentes motivações de uso nos jogadores, seja por sua interação como mesmo ou com o grau de imersão que o jogo pode oferecer. Vale assinalar, em relação ao ambiente midiático (físico) utilizado, que grande maioria dos entrevistados respondeu que o dispositivo mais usado é o computador.

No terceiro bloco, notou-se que os jogadores tiveram o primeiro contato com o jogo por meio de amigos e, depois, pela internet e, posteriormente pelos outros diversos jogos da produtora Blizzard, pois havia extras dos CD- 
-ROM apresentando futuros lançamentos. Foi possível constatar na pesquisa que família e parceiro foram fortes influenciadores para que o jogador tivesse o primeiro contato com o jogo. Sobre a avaliação do enredo de World of Warcraft a maior nota escolhida obtida foi 10 , sendo considerado perfeito para os jogadores.

Figura 2: Avaliação do enredo de World of Warcraft

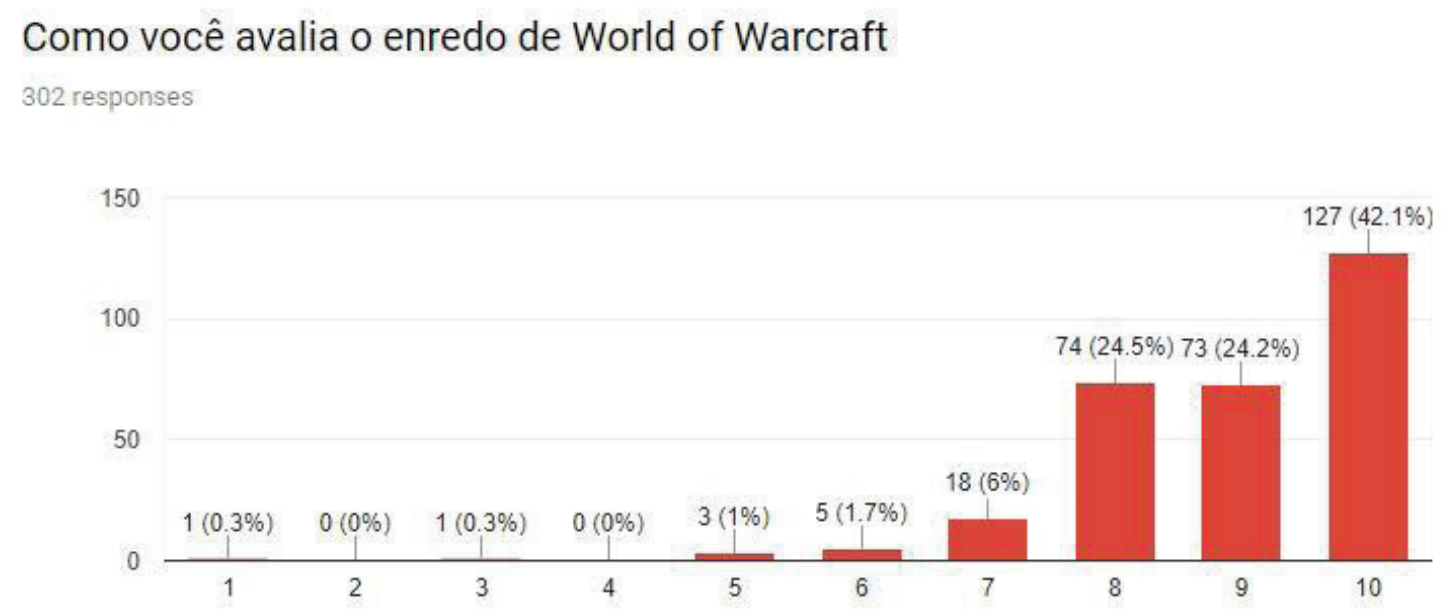

Fonte: dados da pesquisa.

Para próxima pergunta, o que o entrevistado mais gostou da narrativa do jogo, a resposta mais citada foi a própria história ou lore, a maneira que diversos personagens tem uma relação uns com outros, da história da criação do mundo de Azeroth em geral, em que o bem e o mal dependem do ponto de vista do jogador. Piccini (2012) reconhece que, no âmbito da narrativa de um jogo digital, existe um universo complexo que propicia aos jogadores maior viabilidade de promover diferentes interpretações e contribuir para o processo de construção de sistemas de valores presentes no jogo. Jogadores também jogam com diversas classes para aprender suas histórias, apresenta uma história em particular e única. A narrativa do jogo contribuiu para o consumo de outras mídias, não restringindo os consumidores, portanto, somente à história apresentada no jogo, possibilitando, por meio dos livros e do filme um complemento mais abrangente deste universo.

Para o objetivo do quarto e último bloco da pesquisa, tem-se a transmídia em destaque. A Horda aparece sendo a facção mais jogada pelos entrevistados. É possível analisar que jogo e livro mantêm médias 10 e 8 respectivamente, diferente do filme, que mantêm uma média de 6 e 5. Pode-se 
considerar o fato que o roteiro do filme sofreu uma adaptação cinematográfica, alterando partes da narrativa do jogo.

Figura 3: Facção mais jogada

\section{Qual facção você joga?}

\section{2 responses}

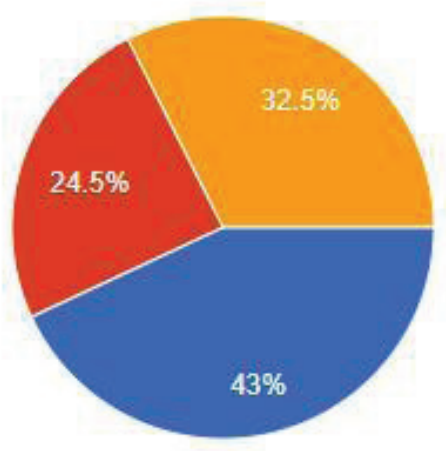

Fonte: dados da pesquisa.

Na questão acerca de ler novamente os livros, observa-se que a opção "Sim" e "Talvez" estão em grande maioria, o que permite afirmar que boa parte dos entrevistados já leram uma significativa fatia do universo literário do jogo. Na pergunta posterior, a respeito de assistir novamente ao filme, o "sim" e o "talvez" aparecem escolhidos pelos jogadores em sua grande maioria. Pode-se dizer que, mesmo a narrativa do filme não tendo uma visão tão positiva, ficando com uma média baixa se comparado ao jogo e aos livros, mesmo assim existe uma possibilidade de ele ser assistido novamente pelos jogadores. Para uma grande maioria de jogadores, jogar novamente os antigos conteúdos do jogo não é nenhum problema, pois, existe um universo a ser explorado e, para diversos jogadores, o importante não é chegar ao nível máximo, mas conhecer e explorar a história, sendo que um dos fatores que os jogadores mais apreciam é a narrativa do jogo em si.

Sobre reconhecer referências do jogo nos livros e no filme, a grande maioria respondeu que "Sim", mas ainda o WoW é tido como principal meio da narrativa de todo universo, sendo as outras mídias percebidas como complementares, criadas para reforçar todo o resto da história. Sobre os jogadores que escolheram o "não" pode-se afirmar que tal escolha pode ter relação com uma não preocupação com a história, em que estes consomem 
a franquia optando por apenas jogar e evoluir, não lendo os livros e nem assistindo ao filme, portanto.

Perguntou-se aos entrevistados se esses reconhecem alguma referência do livro no jogo e no filme. A maioria escolheu a opção "sim". Os livros são utilizados para individualizar histórias de personagens e determinados momentos da narrativa, então é comum durante o decorrer do jogo, encontrar personagens que, ao primeiro encontro, não têm interação com o jogador, mas, se o entrevistado tiver lido determinado livro, é possível conhecer mais a fundo tais personagens. Também é comum jogar determinados momentos do game onde a continuação e os efeitos só são explicados nos livros. Sobre reconhecer a referência do filme no jogo e nos livros, os jogadores marcaram também o "Sim" como maioria das respostas. Durante o período do filme nos cinemas, a produtora Blizzard deu aos jogadores "cosméticos", itens que alteram apenas a aparência de determinada arma ou armadura, para todos os jogadores que permaneceram on-line. Para os livros, foi lançado um prelúdio da história do filme, além da versão do filme em formato de livro. Para Jenkins (2004), isso pode ser caracterizado como embedded narratives, no qual é necessário que o jogador descubra a narrativa decifrando o espaço do jogo, pois, para reconhecer tais referências, é necessário maior exploração do universo do game.

Sobre entender o conteúdo isoladamente, livro, filme e jogo apareceram com a maioria das respostas "sim", mas cada mídia se torna única para o entendimento geral de toda narrativa, necessitando o conhecimento da história de ambas para entender completamente esse universo. Sobre conhecer o conteúdo individual, Jenkins, Green e Ford (2014) defendem que produtos midiáticos devem ser independentes, assim, exigindo maior trabaIho e atenção da equipe de roteiro.

Para última pergunta do questionário, o entrevistado deveria falar qual a primeira palavra que vem à mente quando mencionamos World of Warcraft. Dentre as diversas palavras, as três citadas foram: a da facção "Horda", totalizando 25 citações, acompanhado depois de "História/Lore" com 21 e "Melhor MMORPG" com 15. Logo, quando indagado a respeito de World of Warcraft, o jogador já se posiciona em uma das facções, e são citados os gritos de guerra, For the Horde e For the Alliance, de ambas as facções. Para Costa (2012), ao imergir em um jogo, o jogador passa a crer no mundo virtual e encarar o mesmo como se fosse sua própria realidade, conferindo-lhe diferentes emoções do que sente lendo um livro ou assistindo a um filme. Devi- 
do à extensa lore do jogo, a história é outro fator bastante citado por parte dos entrevistados, existindo um grande fascínio por toda ela, se tornando o segundo item mais recorrente da nuvem de palavras.

Figura 4: Nuvem de palavras

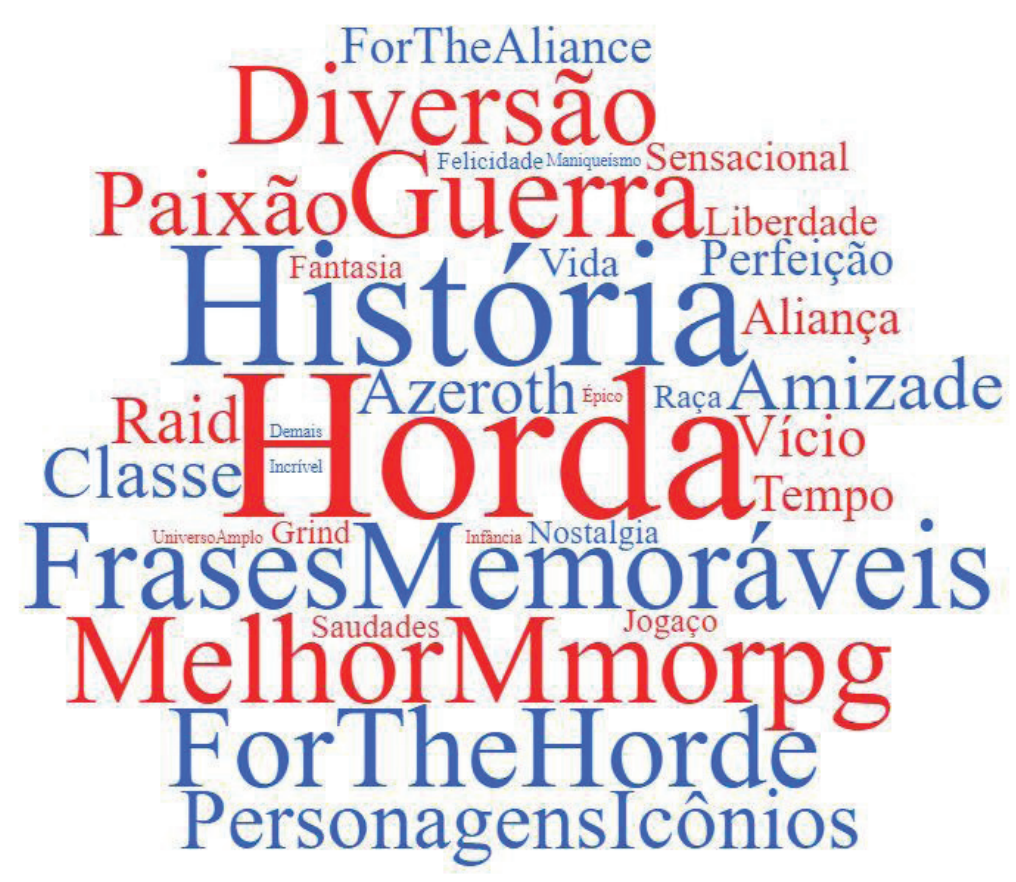

Fonte: dados da pesquisa.

\section{CONSIDERAÇÕES FINAIS}

Este artigo teve como tema o universo de World of Warcraft, com o objetivo geral de estudar os fatores motivacionais que levam os jogadores brasileiros do game a consumirem suas narrativas em diversas mídias e identificar os principais motivos pelos quais ocorre o consumo do game.

Com o resultado alcançado, percebeu-se que o principal fator motivacional que levou os jogadores de World of Warcraft a consumir a franquia é a imersão proporcionada no mundo narrativo do jogo, fazendo com que estejam presentes em um universo único, vivendo cada momento da história como presente pelos acontecimentos testemunhados. Para chegar neste resultado, foi aplicada uma pesquisa de quatro blocos por meio da utilização de um questionário semiestruturado. 
Vale ressaltar que, para os jogadores entrevistados, o principal motivo pelo qual ocorre o consumo do game por parte dos jogadores é a história/ lore apresentada durante todo o jogo. Chega-se a considerar que os livros são partes extremamente importantes para o envolvimento da história por parte dos jogadores, pois, além de explicar determinados momentos críticos, apresentam uma história mais rica em detalhes no universo do jogo. Pondera-se que o filme não apresenta um envolvimento tão grande por parte dos jogadores, pois, comparado às narrativas do jogo e dos livros, ficou abaixo da média, mesmo os entrevistados afirmando que assistiram novamente ao filme. Finalmente, o que influenciou o consumo de mídia não foi a publicidade, mas as diferentes histórias apresentadas em diversas mídias, pois isso possibilitou que o jogador ficasse cada vez mais imerso na lore do jogo.

A principal limitação deste estudo se deve às necessidades de delimitação do contexto de pesquisa. Ao utilizar o Facebook como universo de pesquisa, exclui-se um conglomerado de consumidores que não sejam fãs tão dedicados ao jogo, por exemplo, e apresentem respostas diferentes às perguntas deste trabalho se comparados à média geral dos jogadores. Vale destacar que a amostra foi composta por respostas de jogadores falantes do português. Se fosse realizada noutros países, como, por exemplo, nos Estados Unidos (país de origem do jogo), as respostas poderiam ser diferentes.

Outrossim, vale destacar que o recorte específico que aqui se foi proposto se deve ao fato de que o tema é bastante vasto e diferentes direcionamentos podem ser tomados para futuras pesquisas da mesma forma que o presente estudo não visa esgotar os estudos acerca dessa temática. Portanto, uma das sugestões possíveis é expandir a amostra, alcançando jogadores por diferentes meios a fim de suprimir tendenciosidades (por isso que se buscou explicitar passo a passo as etapas da pesquisa para apresentar maior confiabilidade aos leitores e posteriores possibilidades de verificação). No âmbito desta sugestão de ampliar a abrangência do contexto de entrevistados está a necessidade de captar dados de jogadores de diversos países para se obter uma tendência de caráter global visto que a presente pesquisa esteve centrada em um viés local.

Outro viés é tentar correlacionar os dados de forma entender os padrões subjacentes às respostas. Por exemplo, poderia identificar se os jogadores que tendem a consumir mídias em formatos variados de um mesmo 
universo são aqueles que priorizam a narrativa quando decidem consumir um jogo. Também poder-se-ia buscar entender a sinergia entre publicidade e narrativa, ou seja, como essa faz uso da narrativa para promover o jogo e em que cenários uma se torna mais importante que a outra na promoção do consumo. $O$ que está em questão é que o terreno de reflexões é fértil e múltiplo, rico de possibilidades de inserção e pesquisa. Com o presente trabalho, espera-se, portanto, contribuir ao conjunto de estudos acerca do consumo de narrativas transmídia em contexto nacional principalmente porque ao estudar o consumo estudamos as formas com que as manifestações culturais permeiam a humanidade em instâncias distintas ou gerais que vão entrelaçando sujeitos, histórias e formas de situar-se no mundo.

\section{REFERÊNCIAS}

BARQUETTE, S.; CHAOUBAH, A. Pesquisa de Marketing. São Paulo: Saraiva, 2007.

BILGIHAN, A.; COBANOGLU, C.; NUSAIR, K.; OKUMUS, F.; AND BUJISC, M. A quantitative study exploring the difference between gaming genre preference. The computer Games Journal, v. 2, 19-40, 2013.

BONA, R. J.; SOUZA, M. P. A narrativa transmídia na era da convergência: análise das transposições midiáticas de The walking dead. Razón y Palabra, v. 1, p. 1-16, 2013.

COSTA, J. P. L. Começo, Meio e Fim: uma análise dos elementos de narrativa nos videogames. In.: XI SBGAMES, Brasília, Anais..., p. 52-61, 2012.

COVALESKI, R. Narrativas publicitárias e transmidiação: consumo e conteúdos midiáticos. In: CONGRESSO INTERNACIONAL DE COMUNICAÇÃO E CONSUMO - COMUNICON2015. São Paulo. Anais... p. 1-13, 2015.

FECHINE, Yvana Carla; BRONSZTEIN, Karla Patriota. Consumo transmídias de conteúdo televisivos: exploração em torno de uma agenda de investigações. REVISTA FAMECOS, v. 23, n. 1, 2016.

JENKINS, H. Cultura da convergência. 2a ed. São Paulo: Aleph, 2009.

; GREEN, J.; FORD, S. Cultura da conexão: criando valor e significado por meio da mídia propagável. São Paulo: Aleph, 2014.

JUSTI, J. E.; MILL, D. Narrativas transmidiáticas: A comunicação persuasiva fluindo entre ambientes on e offline. REVISTA GEMInIS. v. 8, n. 2, p. 83, 2017.

LOPES, L. C. R.; MUSTARO, P. N. Uso de redes de Kohonen para identificação de perfis de jogadores no World of Warcraft. ANAIS DO BRAZILIAN SYMPOSIUM ON GAMES AND DIGITAL ENTERTAINMENT. Rio de Janeiro, RJ, Brazil, 8, 2009.

MARTINS, C. A cultura da convergência e a narrativa transmídia. 2009. Disponível em: http://opiniaoenoticia.com.br/vida/tecnologia/a-cultura-da-convergencia-e-a-narrativa-transmidia/. Acesso em: 22 jul. 2018. 
NEWZOO. The global games market reaches $\$ 99.6$ billion in 2016, mobile generating 37\%. Disponível em: https://newzoo.com/insights/articles/global-games-market-reaches-99-6-billion-2016-mobile-generating-37/. Acesso em: 02 out. 2017.

OLIVEIRA, J. K.; MASSAROLO, J. Elementos da construção de mundo articulado em World of Warcraft. REVISTA GEMInIS, v. 2, n. 2, p. 90-102, 2011.

PEREIRA, M. E. P. B.; BONA, R. J. Entre o cinema e os anos de 1980: a percepção das relações intertextuais da primeira temporada de Stranger things pelos jovens espectadores brasileiros. Temática - Revista eletrônica de publicação mensal, v. 2, p. 97-112, 2018.

PICCINI, M. O papel do jogador na construção de sentido em narrativas de jogos digitais: o jogo como forma de expressão do jogador. In.: XI SBGAMES, Brasília, Anais..., p. 197207, 2012.

ROCHA, E. Representações do consumo: estudos sobre a narrativa publicitária. Rio de Janeiro: Ed. PUC-Rio: Mauad, 2006.

SCOLARI, C. A. Narrativas transmedia: cuando todos los medios cuentan. Barcelona: Deusto, 2013.

VIRGILLITO, S. B. Pesquisa de marketing: uma abordagem quantitativa e qualitativa. São Paulo: Saraiva, 2010. 


\section{Rafael Jose Bona}

Doutor em Comunicação e Linguagens (PPGCOM/UTP). Docente do Programa de Pós-Graduação em Educação (PPGE) FURB). Atua nos cursos de graduação e pós-graduação da UNIVALI e da FURB.

E-mail: bona.professor@gmail.com

\section{Éderson Luís da Silveira}

Doutor em Linguística pela Universidade Federal de Santa Catarina (UFSC), graduado em Letras Português pela Universidade Federal do Rio Grande (FURG).

E-mail: ediliteratus@gmail.com

\section{Diogo de Azeredo Leão Coutinho}

Graduado em Publicidade e Propaganda (FURB).

E-mail: diogo-coutinho@hotmail.com 